COMUNICAÇÃO CIENTÍFICA

\title{
CONSERVAÇÃO PÓS-COLHEITA DE MAMÃO FORMOSA COM FILME DE PVC E REFRIGERAÇÃ ${ }^{1}$
}

\author{
TATIANE CRISTELLI DIAS 2 , WAGNER FERREIRA DA MOTA³ ${ }^{3}$ BRUNO DA SILVA OTONI², \\ GISELE POLETE MIZOBUTSI ${ }^{3}$, MARCOS GLEIDSON PEREIRA DOS SANTOS ${ }^{2}$
}

RESUMO - O objetivo deste trabalho foi aumentar a vida útil pós-colheita de frutos de mamão, mantendo sua qualidade com utilização de filme de PVC, de $12 \mathrm{~mm}$ de espessura, e refrigeração. Foram utilizados mamões do grupo Formosa Tainung 01. A temperatura refrigerada foi de $10^{\circ} \mathrm{C}$ e umidade relativa do ar de $90 \%$. A temperatura ambiente foi $25^{\circ} \mathrm{C}(+/-1)$ e umidade relativa em torno de $60 \%$. O delineamento utilizado foi o de blocos casualizados. As menores perdas de massa fresca ocorreram com uso de $\mathrm{PVC}$ a $10^{\circ} \mathrm{C}$. $\mathrm{O}$ uso da refrigeração a $10^{\circ} \mathrm{C}$ condicionou maior firmeza, além de menores teores de sólidos solúveis totais e elevação da relação SST ATT ${ }^{-1}$ até o $6^{\circ}$ dia de armazenamento, seguida de estabilização. O armazenamento de mamão Formosa sob refrigeração, associado com filme de PVC, foi mais eficiente na manutenção da qualidade dos frutos, proporcionando maior tempo de vida útil.

Termos para indexação: Carica papaya, atmosfera modificada, armazenamento.

\section{POST-HARVEST CONSERVATION OF FORMOSA PAPAYA WITH PVC FILM AND REFRIGERATION}

\begin{abstract}
The objective of this work was to increase post-harvest preservation of papaya fruit maintaining its quality with use of PVC film and refrigerated temperature. It was used papayas from the group Formosa, Tainung 01 . The temperature of cooling used was $10^{\circ} \mathrm{C}$ and relative humidity of $90 \%$. The ambience temperature was $25^{\circ} \mathrm{C}(+/-1)$ with relative humidity around $60 \%$. The experimental design was randomized blocks. The lowest percentages of fresh mass loss were observed in the treatment with PVC at $10^{\circ} \mathrm{C}$. The refrigeration use at $10^{\circ} \mathrm{C}$ had higher firmness, lower levels of total soluble solids and growing increase of SST ATT ${ }^{-1}$ until the 6th day of storage, with next phase of stabilization. The storage of papaya Formosa under refrigeration associated with modified atmosphere with PVC film was more efficient in maintaining the quality of the fruit.
\end{abstract}

Index terms: Carica papaya, modified atmosphere, storage.

O mamão 'Formosa' é destinado principalmente para o mercado interno, obtendo melhores preços de julho a agosto. Os frutos provenientes de árvores hermafroditas são preferidos pelos consumidores por possuírem menor cavidade interna (ROCHA, 2003). Em 2005, o Brasil foi o maior produtor mundial, com 1.650 mil toneladas (FAO, 2007).

$\mathrm{O}$ fruto do mamoeiro apresenta respiração climatérica, pois a maturação continua após a colheita. Para consumo, os frutos devem ser colhidos após a maturação fisiológica e antes da sua total maturação, pois esses apresentam altas taxa respiratória e produção de etileno após colhidos. Estas características conferem-lhes rápida perecibilidade quando mantidos em temperatura ambiente. Portanto, o controle do amadurecimento é essencial para elevar a conservação, principalmente quando o objetivo é comercializar em mercados mais distantes (PEREIRA et al., 2006).

Em geral, a atmosfera modificada reduz as taxas de respiração, produção e ação do etileno, retardando a maturação do produto, pois cria atmosfera com baixos níveis de $\mathrm{O}_{2}$ e altos de $\mathrm{CO}_{2}$. Embora muitos filmes plásticos de diferentes permeabilidades a gases sejam utilizados, os filmes à base de polietileno ou policloreto de vinila (PVC) são os mais usados pela praticidade, custo baixo e eficiência em frutos e hortaliças (CHITARRA; CHITARRA, 2005).

\footnotetext{
1(Trabalho 135-10). Recebido em: 01-06-2010. Aceito para publicação em: 07-04-2011.

${ }^{2}$ Acadêmicos do Curso de Agronomia da UNIMONTES, Centro de Ciências Exatas e Tecnológicas, Departamento de Ciências Agrárias, 39440-000, Janaúba-MG. E-mails: tatianecristelli@yahoo.com.br, agronomiabruno@bol.com.br;gleidsonagron@yahoo.com.br ${ }^{3}$ Professor e Bolsista da FAPEMIG do Departamento de Ciências Agrárias da Universidade Estadual de Montes Claros/UNIMONTES, E-mail:wagner.mota@unimontes.br, gisele.mizobutsi@unimontes.br,
} 
A refrigeração é o método mais econômico para o armazenamento prolongado de frutos e hortaliças. O objetivo principal da refrigeração é reduzir a taxa metabólica do fruto e prolongar sua vida útil, permitindo o transporte via marítima. Além disso, a refrigeração também exerce o efeito de suprimir o desenvolvimento de patógenos. Entretanto, temperaturas muito baixas podem causar problemas de congelamento, e temperaturas muito elevadas ocasionarão redução do tempo de armazenamento. Grandes flutuações da temperatura podem resultar na condensação de água sobre o produto, o que favorece o aparecimento de doenças (FONSECA et al., 2003). Geralmente a utilização do filme de PVC torna-se mais eficiente quando está associada à refrigeração, pois promove aumento considerável na vida de prateleira dos frutos em função do acúmulo dos benefícios dessas duas técnicas.

A demanda pelo mamão Formosa vem aumentando no Brasil e, consequentemente, a produção também. Por outro lado, grande parte desse mamão produzido é transportado e comercializado a granel, sem utilização de embalagem, muito menos sob revestimento individual dos frutos em atmosfera modificada com filme de PVC, por isso as perdas chegam até a 20,3 \% (SANTOS et al., 2008). Desta forma, em função dos escassos trabalhos sobre conservação pós-colheita, o objetivo do presente trabalho foi estudar a vida útil pós-colheita de frutos de mamão "Formosa", mantendo sua qualidade com revestimento individual em atmosfera modificada com filme de PVC associado com refrigeração.

Foram utilizados mamões do grupo Formosa, cultivar Tainung $\mathrm{n}^{\circ} 1$, oriundos de pomar comercial de Nova Porteirinha-MG, colhidos em estágio de maturação comercial para a exportação, com até $25 \%$ da superfície da casca amarela, rodeada de verde-claro. Após colhidos, os frutos foram embalados em folhas de jornal e acondicionados em caixas de papelão. Em seguida, foi realizada a seleção de acordo com a uniformidade de cor, tamanho e ausência de injúrias. Posteriormente, os frutos foram transportados ao laboratório de pós-colheita da Universidade Estadual de Montes Claros, Câmpus de Janaúba-MG. Os mamões foram lavados com hipoclorito de sódio a $0,5 \%$ e colocados para secar. Posteriormente, foram acondicionados em bandejas de isopor sem (testemunha) e com filme de PVC esticável e autoaderente ( $0,015 \mathrm{~mm}$ de espessura, marca Rolopack) e permeabilidade a $\mathrm{O}_{2}$ e $\mathrm{CO}_{2}$ de 620 e $4.263 \mathrm{~cm}^{3} \mathrm{~m}^{2} \mathrm{dia}^{-1}$, respectivamente. Em seguida, as bandejas foram armazenadas em câmaras frias $\left(10 \pm 2^{\circ} \mathrm{C}\right.$ e $90 \pm 5 \%$ de UR) e ambiente $\left(22 \pm 2^{\circ} \mathrm{C}\right.$ e $80 \pm 5 \%$ de UR).

O delineamento experimental utilizado foi o de blocos casualizados, com quatro repetições e quatro frutos por unidade experimental. Foi utilizado um esquema de parcelas subdivididas, apresentando nas parcelas um fatorial 2 (embalagens com e sem PVC) x 2 (temperaturas ambiente e $10^{\circ} \mathrm{C}$ ) e, nas subparcelas, as cinco épocas de armazenamento, em intervalo de seis dias, perfazendo 24 dias de armazenamento.

Para o cálculo da perda de matéria fresca do fruto (PMF), a diferença de massa entre as avaliações foi acumulada durante a evolução do experimento, e o resultado da perda de massa fresca em relação à massa inicial do fruto, expresso em porcentagem.

A firmeza da polpa (Newtons $-\mathrm{N}$ ) foi obtida com penetrômetro manual marca Fruit Pressure Tester e as medidas foram tomadas em três pontos da superfície do fruto, nas extremidades e na região equatorial, após retirada da casca.

A determinação dos sólidos solúveis (SS) foi feita por refratometria, utilizando-se de refratômetro de campo (Atago, modelo N-1 $\alpha$, com leitura na faixa de 0 a $95^{\circ}$ Brix), e os resultados foram expressos em ${ }^{\circ}$ Brix.

A acidez titulável (AT) foi determinada pela técnica recomendada pela AOAC (1992), titulandose suco, sob agitação, com $\mathrm{NaOH} 0,1 \mathrm{~N}$, usando-se, como indicador, fenolftaleína a $1 \%$. O resultado foi expresso em g eq. ácido cítrico $100 \mathrm{~g}^{-1}$ suco.

A relação sólidos solúveis/acidez titulável (RSA) foi obtida pela divisão das variáveis.

Foram realizadas análise de variância e regressão para os fatores quantitativos. Os fatores qualitativos foram comparados, utilizando-se o teste de Tukey, a $5 \%$ de probabilidade.

Houve elevação da PMF durante o armazenamento (Figura 1A). Solon et al. (2005) também verificaram, no armazenamento de mamão formosa, PMF crescente ao utilizar cera de carnaúba ou embalagens de poliamidas a $10^{\circ} \mathrm{C}$ e a $90 \%$ UR. Já An e Paul (1990) verificaram com mamão papaya, que a PMF foi de $13 \%$ ao final de dez dias de armazenamento a $30^{\circ} \mathrm{C}$.

Perdas de matéria fresca (PMF) acima de 5\% são suficientes para depreciar o mamão (SANTOS et al., 2008). Neste trabalho, esse nível (5\%) de PMF ocorreu aos $3 ; 11 ; 14$ e 15 dias após a colheita nos armazenamentos sem e com PVC ao ambiente e sem e com $\mathrm{PVC}$ a $10^{\circ} \mathrm{C}$, respectivamente, demonstrando que as menores PMF, que condicionam períodos mais prolongados para atingir $5 \%$ de perda, foram detectadas nos armazenamentos sem e com PVC a $10^{\circ} \mathrm{C}$. Morais et al. (2010) também verificaram maior eficiência dessa temperatura em associação com filme de Polyamida X-tend na conservação de mamão formosa. Possivelmente, essa maior efici- 
ência ocorreu pelo surgimento de ambiente saturado de umidade na embalagem, reduzindo o gradiente de pressão de vapor de água entre os frutos e a atmosfera da embalagem (MOTA et al., 2003). A redução da temperatura elevou a eficiência desses tratamentos, possivelmente por ter reduzido a troca gasosa com o meio, reduzindo a respiração (FINGER et al., 2008). Rocha et al. (2005) também verificaram aumento na PMF em mamão Formosa, com o aumento do período de armazenamento e das temperaturas, verificando maior eficiência no armazenamento a $8^{\circ} \mathrm{C}$ e $10^{\circ} \mathrm{C}$.

Observa-se que a firmeza da polpa correlacionou-se à PMF, sendo mais bem preservada nos tratamentos conservados em temperatura refrigerada (Figura 1B). Eficiência também foi demonstrada na conservação de mamão formosa a $10^{\circ} \mathrm{C}$ (ROCHA et al., 2005). A manutenção de maior firmeza em refrigeração pode ser explicada pela redução da atividade da poligalacturonase, que está relacionada ao amadurecimento. Essa maior firmeza notada nos frutos refrigerados poderá garantir aos frutos melhor resistência a danos mecânicos durante o manuseio e, consequentemente, maior durabilidade.

Os tratamentos mantidos em temperatura refrigerada mantiveram menores teores de SS (Figura 1C). Rocha et al. (2007) também estimaram o maior conteúdo de SS nos frutos submetidos à temperatura de $10{ }^{\circ} \mathrm{C}$, até 22 dias de armazenamento, enquanto o menor foi em temperaturas de 8 e $12^{\circ} \mathrm{C}$, de 25 a 31 dias de armazenamento. Solon et al. (2005) também observaram que frutos conservados em atmosfera modificada e refrigerados apresentaram pequena diminuição na concentração de SS ao longo do tempo de armazenamento.

O uso da refrigeração reduz a atividade respiratória, tendo como consequência menores hidrólises dos carboidratos de reserva acumulados durante o crescimento da planta e produção de açúcares solúveis e, consequentemente, menor amadurecimento (MOTA et al., 2003), mantendo esta característica qualitativa do flavor por maior período, colaborando para o tempo de comercialização. Já os frutos armazenados ao ambiente, especialmente sem PVC, estariam no nível ótimo de consumo, com maior teor de SS. Pois, os valores reportados neste trabalho, acima de $9 \%$, estão dentro da faixa de comercialização exigida para frutos 'Formosa', que é de 9,0 a 12\% (FAGUNDES; YAMANISHI, 2001), não havendo mais tempo para comercialização.

O mamão apresentou mudança na acidez durante o armazenamento. Dessa forma, a AT foi reduzida consideravelmente até o $8^{\circ}$ dia, com estabilização a partir daí (Figura 1D). Rocha et al. (2007), trabalhando com mamão formosa refrige- rado, também verificaram redução da ATT durante o armazenamento, embora tenham observado uma pequena elevação após os 28 dias. Fonseca et al. (2003) não verificaram diferenças na acidez titulável entre tratamentos, em mamão Golden armazenado em temperatura ambiente e a $10^{\circ} \mathrm{C}$; desta forma, não houve redução do metabolismo dos frutos. Já Morais et al. (2010) verificaram leve aumento da acidez durante o armazenamento de mamão formosa a $10^{\circ} \mathrm{C}$ com filme de Polyamida X-tend, pois os mesmos colheram com $10 \%$ de coloração, estando em fase de amadurecimento.

Os valores obtidos no presente trabalho, em relação ao teor de AT, confirmam que, após a colheita, a concentração de ácidos orgânicos tende a declinar na maioria dos frutos, devido à larga utilização desses compostos como substrato respiratório e como esqueletos de carbono, para a síntese de novos compostos (SÓLON et al., 2005).

Observou-se elevação da relação $\mathrm{SS} \mathrm{AT}^{-1} \mathrm{em}$ todos os tratamentos, até o $6^{\circ}$ dia de armazenamento; posteriormente, houve fase de estabilização para os tratamentos conservados a $10^{\circ} \mathrm{C}$, apresentando ao final dos 24 dias de armazenamento maiores relação SST ATT ${ }^{-1}$, especialmente o tratamento sem PVC, com maior relação. Nos demais tratamentos, em temperatura ambiente, observou-se um leve declínio no terço final do armazenamento, onde os frutos com PVC apresentaram menor relação (Figura 1E).

Os SS normalmente elevam com o avanço da maturação, enquanto a AT são reduzidos, sendo assim, a relação $\mathrm{SS} \mathrm{AT}^{-1}$ é diretamente proporcional aos SS e inversamente a AT. A relação SS AT ${ }^{-1}$ é mais representativa que a medição isolada de açúcares ou acidez, pois a relação dá uma boa ideia do equilíbrio entre esses componentes (CHITARRA;CHITARRA, 2005).

O armazenamento de mamão Formosa sob refrigeração, associado a atmosfera modificada com filme de PVC, foi mais eficiente na conservação pós-colheita e manutenção da qualidade dos frutos, proporcionando maior vida de prateleira. 

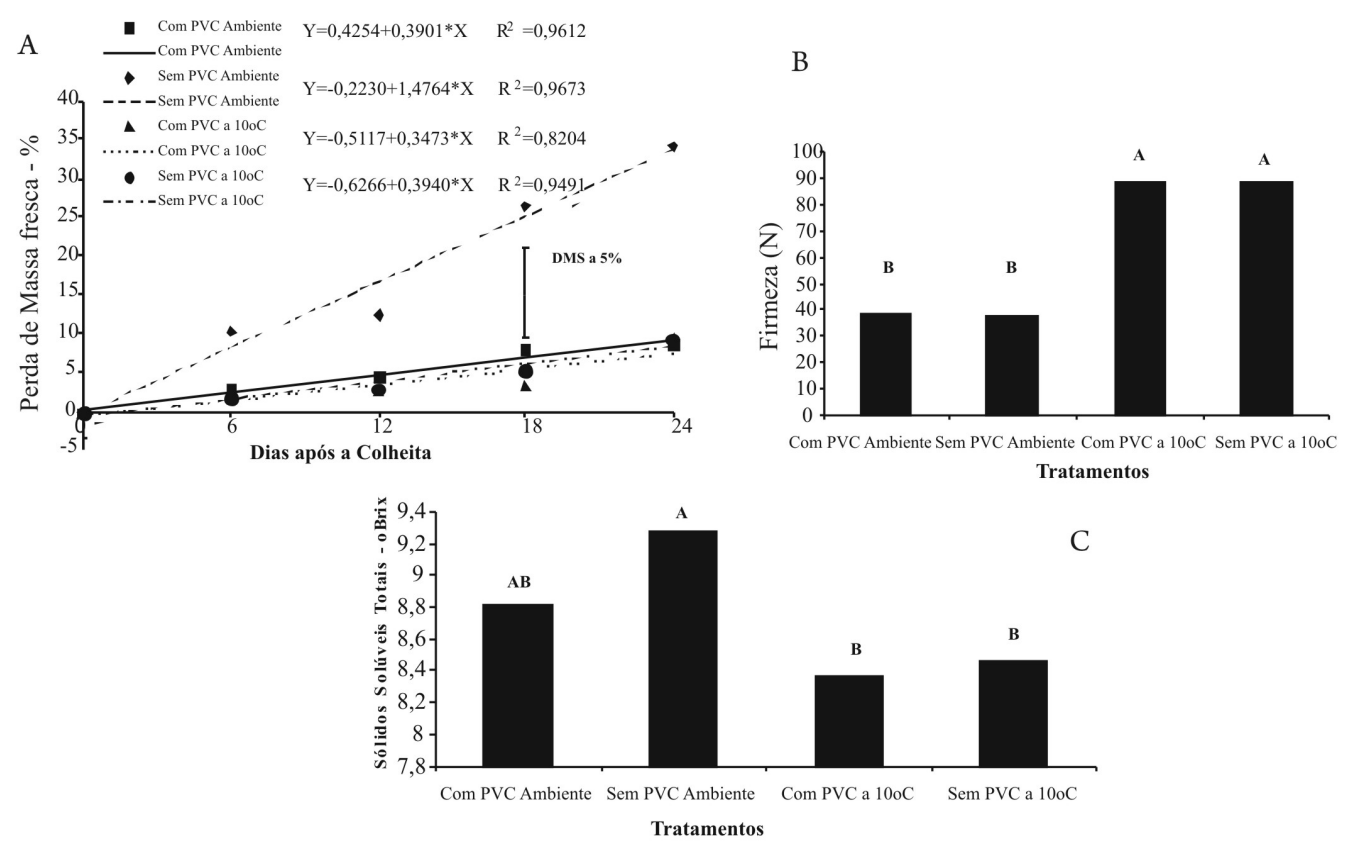

$\mathrm{D}$

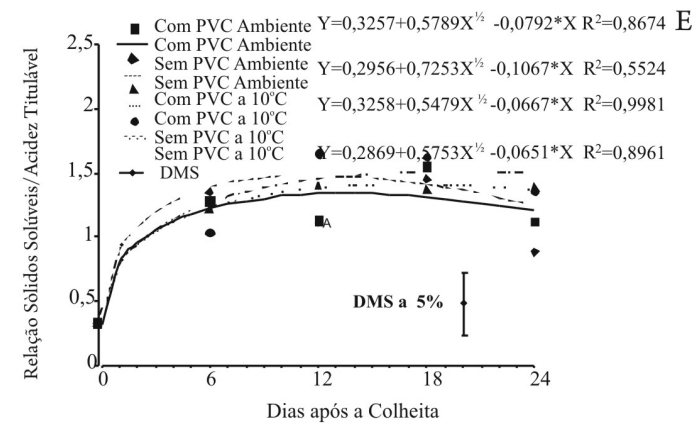

FIGURA 1 - Variação do percentual de perda de matéria fresca, firmeza, teor de sólidos solúveis totais, acidez total titulável (ATT) e relação brix/acidez dos frutos de mamão em função da época de avaliação e tratamentos armazenados em temperaturas ambiente e a $10^{\circ} \mathrm{C}$, com e sem PVC. 


\section{REFERÊNCIAS}

AN, J.F.; PAULL, R.E. Storage temperature and ethylene influence on ripening of papaya fruit. Journal of the American Society for Horticultural Science, Alexandria, v. 115, n. 6, p. 949-953, 1990.

AOAC - Association of Official Analytical Chemistry. Official methods analysis the Association of Official Analytical Chemistry. $12^{\text {th }}$ ed. Arlington, 1992.

CHITARRA, M.I.F.; CHITARRA, A. B. Pós-colheita de frutas e hortaliças: fisiologia e manuseio. 2. ed. Lavras: UFLA, 2005. 785 p.

FAGUNDES, G. R.; YAMANISHI, O. K. Características físicas e químicas de frutos de mamoeiro do grupo "Solo" comercializados em 4 estabelecimentos de Brasília-DF. Revista Brasileira de Fruticultura, Jaboticabal, v.23, n.3, p.541-545, 2001.

FAO - Food and Agriculture Organization. Disponível em: $<$ http://www.fao.org $>$. Acesso em: 01 ago. 2007.

FINGER, F.L.; DELLA-JUSTINA, M.E.; CASALI, V.W.D.; PUIATTI, M. Temperature and modified atmosphere affect the quality of okra. Scientia Agricola, Piracicaba, v.65, p.360 - 364, 2008.

FONSECA, M.J. de O.; CENCI, S.A.; LEAL, N.R.; BOTREL N. Uso de atmosfera controlada para conservação pós-colheita do mamão golden. Revista Brasileira de Fruticultura, Jaboticabal, v. 25, n. 3, p. 537-539, 2003.

MORAIS, F.A.; ARAÚJO, F.M.M.C.; MACHADO, A.V.; RICARTE, F.D.N.; SALES JUNIOR, R. Influência da atmosfera modificada sob a vida útil pós-colheita do mamão 'Formosa'. Revista Verde, Mossoró, v.5, n.4, p. 01-09, 2010
MOTA, W.F.; SALOMÃO, L.C.C.; NERES, C.R.L.; MIZOBUTSI, G.P.; NEVES, L.L.M. Uso de cera de carnaúba e saco plástico poliolefínico na conservação pós-colheita do maracujá-amarelo. Revista Brasileira de Fruticultura, Jaboticabal, v. 28, n. 2, p. 190-193, 2006.

PEREIRA, M.E.C.; SILVA, A.S.; BISPO, A.S.R.; SANTOS, D.B.; SANTOS, S.B.; SANTOS, V.J. Amadurecimento de mamão Formosa com revestimento comestível à base de fécula de mandioca. Ciência e Agrotecnologia, Lavras, v.30, n.6, p.11161119, 2006.

ROCHA, R.H.C. Qualidade e vida útil pós-colheita do mamão Formosa 'Tainung 01'armazenado sob refrigeração . 2003. 64f. Dissertação (Mestrado em Fitotecnia) - Escola Superior de Agricultura de Mossoró, Mossoró, 2003.

ROCHA, R.H.C.; MENEZES, J.B.; NASCIMENTO, S.R. de C.; NUNES, G.H. de R. Qualidade do mamão formosa submetido a diferentes temperaturas de refrigeração. Caatinga, Mossoró, v.20, n.1, p.75-80, 2007.

ROCHA, R. H. C.; NASCIMENTO, S.R.C.; MENEZES, J.B.; NUNES, G.H.S.; SILVA, E.O. Qualidade pós-colheita do mamão Formosa armazenado sob refrigeração. Revista Brasileira de Fruticultura, Jaboticabal, v.27, n. 3, p. 386-389, 2005.

SANTOS, C.E.M.; COUTO, F.A.D.; SALOMÃO, L.C.C.; CECON, P.R.; WAGNER JÚNIOR, A.; BRUCKNER, C.H. Comportamento pós-colheita de mamões formosa 'Tainung 01' acondicionados em diferentes embalagens para o transporte. Revista Brasileira de Fruticultura, Jaboticabal, v.30, n.2, p.315-321, 2008.

SOLON, N.K.; MENEZES J.B.; MEDEIROS, M.K.M. de; AROUCHA, E.M.M.; MENDES, M. de O. Conservação Pós-colheita do Mamão Formosa Produzido no Vale do Assu Sob Atmosfera Modificada. Caatinga, Mossoró, v.18, n.2, p.105-111, 2005. 